\title{
APORTES TEÓRICOS PARA UM ESTUDO SOBRE A PARTICIPAÇÃO NA COMUNICAÇÃO
}

\section{Theoretical supports to a study about the participation in the communication}

\author{
Cláudia Regina Lahnia, Fernanda Coelho da Silvab, \\ Maria Fernanda França Pereirac, Mariana Zibordi Pelegrinin ${ }^{\mathrm{d}}$
}

\footnotetext{
a Professora da graduação e do mestrado daFaculdade de Comunicação Social (UFJF), Mestra eD outora(ECA-USP), São Paulo, SP - Brasil, email: crlahni@ yahoo.com.br

b Mestranda da Faculdade de Comunicação Social (UFJF), Juiz de Fora, MG - Brasil, email: fernandahauck@ yahoo.com.br

${ }^{\text {c }}$ Mestranda da Faculdade de Comunicação Social (UFJF), Juiz de Fora, MG - Brasil, email: fernandinha_fp@ yahoo.com.br

d Mestranda da Faculdade de Comunicação So cial (UERJ), Rio de Janeiro, RJ - Brasil, email: marianapelegrini@ superig.com.br
}

\begin{abstract}
Resumo
A comunicação comunitária é peça fundamental do exercício da cidadania. Para afirmação da participação no processo comunicacional em um meio é necessário que o indivíduo atue na produção de mensagens e reflita sobre a informação que está recebendo. Os meios comunitários, porém, nem sempre constituem um espaço de comunicação para a cidadania. Para verificar tal questão, este grupo de alunas engajadas na iniciação científica, sob a orientação de professora que trabalha nessa área, pesquisa a presença e participação de adolescentes na comunicação e a importância disso para sua cidadania. Neste trabalho, portanto, discorremos sobre fundamentos teóricos que fundamentam pesquisas sobre a participação na comunicação.
\end{abstract}

Palavras-chave: Cidadania; Comunicação comunitária; Rádio.

\begin{abstract}
The community communication has a fundamental role to citizenship exercising. It is necessary to the assertion of the participation in the communicational process in a milieu that the individual acts in the messages production and thinks about the received information. The community environments, however, not always constitute a communication space to the citizenship. In order to verify such question, this group of students involved in scientific initiation, under orientation of a teacher who works in such area, researches the adolescent's presence and participation in communication. In this study, therefore, we write about theoretical foundations that support research on the participation in the communication.
\end{abstract}

Keywords: Citizenship; Community communication; Radio. 


\section{INTRODUÇÃO}

A participação na comunicação tem sido apontada como uma maneiraimportante de exercer cidadania. Em um processo comunicacional, os participantes trocam informações, refletem 0 conteúdo novo e o transformam em outro conhecimento a partir de suas vivências e bagagem cultural. D essa forma, o indivíduo constitui uma formação reflexiva e não imposta. Como os meios, em geral, não proporcionam tal reflexão do conteúdo exposto pela mídia e tampouco a participação direta na elaboração de uma mensagem, a comunicação comunitária, por intermédio das rádios, pode ser um espaço para esse exercício.

Nesse contexto, Cicília Peruzzo e Mario Kaplún são pesquisadores de referência quanto à comunicação comunitária e para a cidadania. Cientes do papel que a comunicação pode representar na sociedade, os teóricos apontam a organização popular como uma das principais consequências da participação direta no processo de comunicação. Além de apresentarem exemplos práticos da atuação dos meios alternativos.

Os meios comunitários, todavia, nem sempre constituem um espaço de comunicação para a cidadania. Para verificar tal questão, em Juiz de Fora, este grupo de alunas engajadas na iniciação científica, sob a orientação de professora que trabalha nessa área, pesquisa a presença e participação de adolescentes na comunicação, de forma específica nas três rádios autorizadas como comunitárias do município. Neste trabalho, apresentamos marcos teóricos que fundamentam esta pesquisa (LAHNI, 2005).

\section{MATERIAIS E MÉTODOS}

0 método utilizado para realização deste artigo foi basicamente revisão bibliográfica. Os autores aqui citados têm o tema da comunicação comunitária no cerne de seus trabalhos.

\section{RESULTADOS}

\section{Kaplún: a busca de uma comunicação horizontal e de uma sociedade democrática}

Falar de Kaplún ao tratar da comunicação comunitária é importante por conta do olhar que 0 autor expôs sob a teoria e a prática dessa ciência. 0 sentido e a aplicação da comunicação é muito maior do que o modelo de massa ao qual os países da América Latina são expostos. Kaplún, ao enxergar que a comunicação não procede senão em um diálogo, foi ainda mais fundo e esboçou o que seria umarededecomunicação, assim como suaeficiência.

A comunicação forma e organiza as pessoas. Essa foi sua conclusão ao analisar a importância dessa ciência no âmbito dos movimentos populares. Tal organização e formação são parte do processo de educar. D esde modo, ao longo de sua trajetória como teórico e defensor da práxis, percebeu a intensa ligação entre essas duas ciências, que são interdisciplinares e indissociáveis.

Estetexto aspiraaconvertirseen un instrumento de trabajo de aquellos comunicadores y estudiantesanimadosporunainquietudeducativa; de quienes ven la Comunicación no sólo como una profesión y un medio de vida sino como algo más: como un servicio a la sociedad. Una prácticaprofesional asíentendidano sólo requiere conocer y dominar los recursos mediáticos; necesita sustentarse en una pedagogía comunicacional. (KAPLÚN, 1998, p. 6).

Kaplún tratou da comunicação entre os grupos ou movimentos populares, sejam eles situadosno meio rural ou urbano. Uma comunicação que acontece com uma frequência que não a física, da qual os movimentos promovem um encontro com uma data e local para discutir questões referentes à matriz e filiais. Nessas reuniõ̃es nem todas as pessoas podem comparecer, deste modo é comum nos movimentos populares uma liderança representar o grupo. Ainda assim é um meio exclusivo, pois não dá voz aos outros integrantes. Os recursos tecnológicos, por mais que auxiliem na quebra defronteiras, constituem equipamentos com 
um custo muito além do qual os movimentos populares podem bancar, assim como os que atuam nessas organizações.

Com isso, além de pensar na importância da comunicação dos movimentos populares, Kaplún tenta instituir uma comunicação que agisse como um instrumento de todos, que fizesse com que cadaintegrante fosse representativo ao discutir as questões referentes ao grupo, sejam elas questões locais ou de âmbito nacional. Que servisse, realmente, como um instrumento de organização, já que 0 diálogo tem 0 propósito de intensificar essa consciência de coletivo, ou seja, ainda que estivessem tratando de locais diferentes, seriam lugares com realidades próximas.

Hoy se empieza a comprender que no habrá desarrollo sin una participación consciente de los sectores populares, en que la que éstos se dinamicen, asuman un papel protagónico y se hagan los creadores de sus propias soluciones. (KAPLÚN, 1984, p. 10).

Kaplún acredita que a comunicação atua diretamente no desenvolvimento dos movimentos populares, estimulando a integração e sintonia entre os grupais, incentivando a participação de todos os integrantes, fazendo com que estes tenham contato com as ideias das lideranças e a partir dessas ideias formulem seus pensamentos e opiniões.

Porém, o modelo de comunicação que predomina não concede aos movimentos populares essa característica de diálogo plural e constante. O modelo "emissor - receptor", de acordo com o teórico, soa falso. Não estabelece uma forma de comunicação, apenas transmite uma informação.

La verdadera comunicación no está dada por un emisor que habla y un preceptorrecipiente que escucha, sino por dos seres 0 comunidades humanas que dialogan (aunque sea distanciay através demedios artificiales). (KAPLÚN, 1984, p. 14).
D amesmaforma acontece com o modelo educacional. 0 educador é quem detém a palavra e o conhecimento, a ser dividido e escutado pelos estudantes.

El emisor es el educador que habla frente a un educando que debe escucharlo pasivamente. $\mathrm{O}$ es el comunicador que sabe emitiendo su mensaje (su artículo periodístico, su programa de radio, su impreso, su vídeo, etc.) desde su propiavisión, con sus propios contenidos, aun lector (u oyente o espectador) que no sabe y al que no se le reconoce otro papel que el de receptor de la información. Su modo de comunicación es, pues, el MONÓLOGO. (KAPLÚN, 1984, p. 18).

Esse modelo educacional não é difícil de ser aplicado pelos meios. 0 trabalho de educar nas escolas, ou seja, essa comunicação pessoal que existe no aprendizado e no cotidiano pode ser agregada pelos veículos de comunicação. Nesse sentido 0 rádio foi a principal ferramenta de estudo de Kaplún já que é um veículo que qualquer cidadão pode ter acesso e entendimento (só é necessário um sentido, a audição). G rande parte de sua experiência como comunicadoreducador foi elaborada no rádio. Esse foi, inclusive, o preceito para a idealização do cassetefórum (1984) que consistia em estabelecer relações entre a cooperativa central e as de base, com o propósito de trocar soluções que possam ser comuns a mais de um local, ou comunicar problemas que possam ser resolvidos com a ajuda de outros grupos. Para isso, uma fita cassete era utilizada pela matriz de determinado grupo social para armazenar as demandas do movimento. As filiais escutavam e armazenavam suas opiniões e dificuldades. Com isso , o cassete-fórum promovia "la possibilidad de discutir seus problemas comunes y buscarles soluciones entre todos; y la conciencia de integración a la organización que los agrupa" (KAPLÚN, 1984, p. 13), além da desmistificação do meio, envolvimento da juventude - que segundo o teórico possibilita a ascensão de novos dirigentes - e incentiva a participação, já que ela acontece de forma direta. 
0 crescimento e desenvolvimento dos movimentos populares dependem de uma participação consciente, ou seja, de que cada um tome para si o papel de protagonista e, deste modo, crie decisões próprias e evite que estas sejam verticais. Pensando em maior esfera, a educação possui esse mesmo papel na sociedade.

[...] la educación debe preparar más para enfrentarse a lo imprevisto que para cumplir la norma, [...] se requiere el desarrollo de la aptitud para vincularse con los demás; vale decir, laformación deun sujeto eminentemente social. Y, finalmente, la capacidad para pensar y expresarse. (KAPLÚN, 1984, p. 216).

A comunicação para Kaplún constitui muito mais do que a função de informar. Trata-se deum mecanismo de formação, organização social e de difusão de conhecimento. Características nem sempre atuantes nos meios de comunicação de massa, mas que se enquadram na prática da comunicação comunitária.

\section{A participação na comunicação a partir da teoria de Cicília Peruzzo}

A pesquisa de Peruzzo (1999) tem como tema, principalmente, a comunicação comunitária, com ênfase nas rádios livres ecomunitárias, voltada para a formação e estruturação da cidadania. Suas contribuições para o pensamento comunicacional brasileiro são extensas. Em Participação nas Rádios C omunitárias no Brasil, a autora aponta a origem das rádios comunitárias no país. Primeiramente houve um surgimento lúdico das rádios livres, em geral essas rádios eram constituídas por "jovens interessados em praticar a arte radiofônica”. 0 aparecimento dessas rádios ocorreu na década de 70. Vale lembrar que nesse contexto a ditadura vigorava, e os meios de comunicação já sofriam com o oligopólio elitista do país, as concessões de canais atendiam aos interesses políticos do governo.

A pesar do surgimento descompromissado dessa forma de comunicação alternativa, a pesquisadora considera positiva a iniciativa e acredita no seu caráter libertário da dependência dos meios de comunicação massivos:

As rádios livres, mesmo que algumas possam ter sido decorrência de aventura sem maiores pretensões políticas, são, no conjunto, um protesto contra a forma de acesso aos instrumentos massivos e uma tentativa de conquistar a liberdade de expressão a qualquer preço. Elas contribuem para o debate da estrutura anti-democrática dos meios de comunicação demassano Brasil. (PERUZZO, 1999, p. 412).

Peruzzo caracteriza as rádios comunitárias, pelos seguintes fatores:

- não devem ter fins lucrativos e sim ser um produto da comunidade;

- devem ter vínculo orgânico com a realidade local, tratando de seus problemas, interesses e cultura;

- a programação deve ser interativa, permitindo acesso do público ao veículo;

- devem valorizareincentivaraprodução e transmissão de culturas locais;

- devem ter compromisso com a educação e cidadania;

- devem democratizar o poder de comunicar.

Porém a comunicação no Brasil sofre um embate entre a autenticidade de uma comunitária, que atenderia às características apontadas e o uso individualizado, comercial ou ainda a prática de proselitismo político-partidário e religioso. As concessões de rádios comunitárias para outros usos que não o comunitário é comum no país. A partir dessa problemática, a autora distingue os tipos de rádios comunitárias:

1) as eminentemente comunitárias;

2) asqueprestam algum serviço de utilidade pública, mas estão sob controle de poucas pessoas, sendo sua finalidade maior a venda de espaço publicitário;

3) estritamente comercial, similar a emissoras convencionais, sem vínculo direto com a comunidade local, embora às vezes preste serviços de utilidade pública;

4) as que fazem Proselitismo políticoideológico-partidário;

5) e as que se prestam ao Proselitismo religioso. (PERUZZO , 1999, p. 417418). 
Segundo Peruzzo (1999, p. 53), "o espaço da mídia comunitária é um campo conflituoso." Isso porque, além do problema que acabamos de analisar, a rádio comunitária sofre com as pressões das rádios comerciais. Essas têm medo da perda de audiência, em decorrência da aceitação e valorização local que as comunitárias vêm atingindo. Como consequência, isso acarretaria a queda de publicidade na mesma localidade. Por esses motivos as rádios comunitárias muitas vezes são, pejorativamente, chamadas de "piratas".

Para seus opositores... elas são "rádios piratas" ou clandestinas. Essas expressões estão carregadas de conotaçõesideológicas. Q uando são chamadas de comunitárias normalmente se lhes atribui um caráter público. São vistas enquanto engajadasnasatividadescomunitárias e, portanto, portadoras de potencial para contribuir para o desenvolvimento social e na construção da cidadania. Ao serem taxadas de piratas elas são tidas como ilegais, invasoras e perversas. (PERUZZO, 1999, p. 114).

Apesar de todos os contratempos, as rádios comunitárias sobrevivem, porque muitas vezes esse meio dialoga com as especificidades da realidade local em que se encontram os ouvintes, servindo para a complementação e confrontação da grande mídia. Tal sobrevivência se dá também, conforme a autora, pela capacidade de inovar eincorporarnovos canais de expressões, práticas e conteúdos (PERUZZO, 1999).

Já no artigo Mídia local e suas interfaces om a mídia comunitária, Peruzzo (2003a), destaca que a valorização do local na sociedade contemporânea é retomada com mais força com a globalização. A té os grandes meios de comunicação de massa, que sempre deram maior importância às grandes distâncias, passam a valorizar conteúdos locais. Esse interesse pelo local se dá pela percepção de que as pessoas também se interessam pelo mais próximo, pelo que afeta suas vidas mais diretamente. Elas "curtem" a globalização, mas também se interessam em buscar suas raízes, valorizam as coisas da comunidade, 0 patrimônio histórico, cultural e local e querem saber dos acontecimentos que ocorrem ao seu redor. $\mathrm{O}$ local é caracterizado pela proximidade do lugar, pela familiaridade e pela diversidade.

Existe comunidade dentro do espaço local quando algunsdossegmentossociaisaliexistentes apresentarem graus e formas de organização típicas de comunidade, como, por exemplo, fortes laços de cooperação entre os indivíduos, sentimento de pertença, interação, participação ativa dos membros e a conjugação de interesses em comum. (PERUZZO, 2003a, p. 55).

0 percurso feito sobre as rádios comunitárias nos leva ao debate do exercício da cidadania que é promovido pelo meio. A comunicação comunitária traz uma dupla contribuição para os indivíduos que participam desse processo. Mas, antes desse tema, é preciso diferenciar os níveis de envolvimento de um cidadão no processo. 0 primeiro nível seria onde se encontra apenas o mero receptor, no segundo haveria participação nas mensagens (como exemplo, os telefonemas para programas), no terceiro nível, reside a produção e difusão das mensagens; no quarto, ocorre a participação no planejamento, e, por último e de forma mais acentuada de participação e representatividade, seria a atuação na gestão. Esse é o objeto de estudo do artigo D ireito à C omunicação C omunitária, Participação Popular e Cidadania.

Quanto maior o grau de envolvimento do indivíduo com o processo mais lhe é acrescentado. A contribuição dupla acontece na reflexão do conteúdo, onde há uma socialização do conhecimento, valorização das culturas locais e debate público; e no processo de produção, que desmitifica a mídia através de uma educação informal do meio. Esses fatores colaboram para a educação da cidadania.

Embora o direito à comunicação e informação esteja assegurado na Declaração Universal dos Direitos Humanos e na Constituição Brasileira de 1988, muitas vezes, na prática, não funciona. É por isso que a comunicação comunitária surge nesse cenário como meio de resistência. Com a predominância da "aldeia global", podemos pensar a rádio comunitária como obstáculo imposto pela cultura local, e também como seu reforço. Diante da atual conjuntura, da comunicação massiva nas mãos de poucos, temos a comunicação comunitária trabalhando com muita importância junto aos movimentos sociais e populares. De acordo com Peruzzo, os movimentos populares são manifestações e organizações com o objetivo de promover a conscientização, a organização e a ação de segmentos da classe subalterna, visando 
satisfazer interesses e necessidades, pretendem ampliar os direitos de cidadania.

Os meios de comunicação a serviço de interesses populares têm importância para a mobilização, visando à transformação social. Ao divulgar novas fontes de informação, 0 cidadão comum é colocado como protagonista do processo, exercendo sua cidadania. Para a autora, a prática da cidadania não reside apenas no acesso à informação, mas também no acesso ao poder de comunicar, sendo uma condição para ampliação da cidadania.

Na palestra proferida por Peruzzo (2006), Comunicação como D ireito, realizada no $4^{0}$ Encontro Regional de Comunicação (Juiz de Fora, 2006), a palestrante fez um breve histórico sobre a evolução da discussão da comunicação comunitária mundial. D esde 1960 a Unesco já trata do direito à comunicação. Na década de 70 surge a Ordem Mundial de Comunicação (O MIC), ressaltando que o direito à comunicação seria um direito humano, de liberdade e um avanço democrático, porém essa organização não obteve repercussão. Em 2001, na cidade de G enebra, esse debate é retomado com a criação do CRIS (Communication Rights in the Information Society), no Brasil ficou conhecido como Direito à Comunicação na SociedadeInformacional. O principal objetivo do CRISéconvocara sociedade civil para essa discussão. Seu auge foi em 2003, ano em que esse tema é resgatado com muita força pela academia e pelos movimentos sociais. D entro do Fórum Social Mundial, foi criado o FMIC (Fórum Social Mundial da Comunicação) que propõe debates e atividades também sobre a temática da comunicação comunitária.

No artigo Da observação participante à pesquisa-ação em comunicação: pressupostos epistemológicos e metodológicos, Cicilia Peruzzo (2003b) defende a importância da pesquisa participante para contribuir com o exercício da comunicação a favor de uma comunidade. Esse método de pesquisa consiste na inserção do pesquisador no ambiente natural de ocorrência do fenômeno e de sua interação com a situação investigada. A pesquisa participante implica na presença constante do observador, para que ele possa "ver as coisas por dentro", no compartilhamento das atividades do grupo e na necessidade de o pesquisador "assumir o papel do outro" para poder atingir o "sentido de suas ações". O s resultados da pesquisa participante poderiam, por exemplo, ajudara resolverproblemas de comunicação do grupo pesquisado e promover assim, a melhoria da sua qualidade de vida.
$\mathrm{Na}$ área da Comunicação Social, a pesquisa participante passa a ser uma das metodologias usadas, a partir de duas motivações. A primeira delas é a realização de uma pesquisa inovadora de caráter qualitativo que permita atingir elevado grau de profundidade, e a segunda é a preocupação em dar um passo adiante em relação aos estudos críticos - do tipo pesquisa denúncia dos meios de comunicação, que já não satisfazem mais alguns pesquisadores.

As finalidades da pesquisa participante na área da Comunicação são: observar fenômenos importantes, especialmente os ligadosa experiências populares de comunicação voltadas para 0 desenvolvimento social, realizar estudos de recepção de conteúdos da mídia que ultrapassassem os padrões então vigentes e pudessem enxergar mecanismos de apropriação ou de re-elaboração de mensagens partindo dos pressupostos da existência de interferência de outras fontes na formação da representação da realidade (mediações). E, por fim, que os resultados da pesquisa - ou até mesmo o seu processo de realização - pudessem retornar ao grupo pesquisado e ser aplicado em seu benefício.

A pesquisa participante é, então, baseada na interação ativa entre pesquisador e grupo pesquisado e, principalmente, na conjugação da investigação com os processos mais amplos de ação social e de apropriação coletiva do conhecimento com a finalidade de transformar 0 povo em sujeito político.

O método ofereceosresultados dapesquisa para o grupo a fim de agir para a sua melhoria. Esse método, de natureza qualitativa, é extremamente válido para elucidar fatos e conhecimentos que a pesquisa quantitativa não consegue mostrar. Por exemplo, a participação popular nos vários níveis do processo de comunicação.

Quando tratamos de comunicação comunitária nos referimos aos veículos de comunicação que são produzidos por uma comunidade e que têm conteúdo voltado para ela. Para que não haja distorções quanto ao termo comunidade é importante ressaltar, segundo Peruzzo, que uma comunidade não pode ser confundida com bairros ou grupos étnicos, pois ela pressupõe a existência de elos mais profundos enão meros aglomerados humanos, embora alguns grupos étnicos e bairros formem sim, uma comunidade. As comunidades que perduram no tempo são caracterizadas pelo sentimento de 
pertença, participação, interação, objetivos comuns, interesses coletivos acima dos individuais, identidades, cooperação, confiança, cultura comum, etc.

"Comunidade nos dias atuais carrega noções de 'coisas' em comum, de laços fortes entre os membros e de um "movimento" em torno do coletivo que supera as amarras do individualismo" (PERUZZO, 2003a, p. 56). D essa forma, não basta que um meio de comunicação fale das coisas do lugar para ser considerado comunitário. 0 que mais importa são as identidades, o vínculo e a inserção como parte de um processo comunitário mais amplo, ou seja, compromisso com a realidade concreta de cada lugar.

Vale ressaltar que a mídia comunitária é caracterizada pelo papel deprotagonista das pessoas, pelo objetivo de divulgar assuntos específicos das comunidades, que geralmente são esquecidos pela grande imprensa. A estratégia usada para tal é a participação direta das pessoas do lugar. Produtor, redator e locutor são cidadãos comuns, não necessariamente profissionais. Os agentes desse processo comunicativo têm como meta contribuir para o desenvolvimento comunitário e não gerar lucros. Os conteúdos são relacionados à problemática da comunidade; feitos por ela e para ela. As decisões que envolvem o funcionamento do veículo são tomadas por um conselho. 0 veículo busca autonomia em relação ao governo e a outros grupos de interesse.

A expressão comunicação comunitária é de uso recente, certamente numa tentativa de se dar conta às transformações nesse âmbito, ou seja, da passagem de uma comunicação mais centrada no protesto para uma comunicação mais plural e de conteúdo abrangente. (PERUZZO, 2003a, p. 59).

No caso específico da rádio comunitária, 0 alcance é bastante limitado já que a rádio deve atingir apenas a comunidade em que está instalada.

Mais do que uma questão de tamanho ou de alcance, o quefaz mais sentido nacompreensão da comunicação comunitária no Brasil e na América Latina é a Confluência de propósitos e o tipo de ação concreta que é desenvolvida em diferentes partes, mas que se encontram no objetivo estratégico do desenvolvimento social. (PERUZZO, 2003a, p. 60).
É importante perceber que a comunicação comunitária é aquela gerada no contexto de mobilização e organização social dos segmentos excluídos, com a finalidade de superar as desigualdades einstaurarmaisjustiçasocial, processo esse que se dá pela participação na comunicação de forma democrática e popular.

\section{Possibilidades de cidadania}

A partir daação direta de uma comunidade nos meios alternativos, o seu espaço de atuação na sociedade é ampliado. A organização de meios alternativos garante a manutenção da prática de comunicação. Além disso, os participantes tornamse protagonistas de suas necessidades e atuam de forma direta na conscientização de seus direitos e na garantia de serem respeitados. 0 espaço de participação na comunicação transforma-se em um canal permanente pelos meios alternativos.

A comunicacão comunitária aponta para várias possibilidades deengajamento social. Como vimos, a partir de trabalhos de Peruzzo e Kaplún, podemos elencar os seguintes conceitos quanto à participação na comunicação:

1) a participação na comunicação deve ser buscada paraatransformação social;

2) a participação pode levar à leitura crítica dos meios;

3) rádios comunitárias para serem este espaço precisam ter canais abertos constantes para a participação.

Sem esses critérios, a comunicação comunitária pode apenas reproduzir o processo dos meios massivos, ou seja, o repasse de informações de qualquer natureza, de forma vertical. E é exatamente essa a análise que vem sendo realizada das rádios autorizadas como comunitárias, em Juiz de Fora, se atuam, ou não, a partir dos conceitos mencionados, como peças fundamentais da comunicação para a cidadania.

\section{AGRADECIMENTOS}

Este trabalho contou com o apoio do $\mathrm{CNPQ}$, financiador da bolsa de iniciação científica PIBIC; da UFJF, financiadora da bolsa de iniciação científica BIC e do MEC - Sesu, financiador da bolsa PET. 


\section{REFERÊNCIAS}

KAPLÚN, Mario. Comunicación entre grupos: el método del cassette-foro. Bogotá: Centro Internacional de Investigaciones para el Desarrollo, 1984. p. 189.

.Una pedagogía de la comunicación. Madri: Ediciones de la Torre, 1998. p. 252.

LAHNI, Cláudia Regina. Possibilidades de cidadania associadas à rádio comunitária juizforana Mega FM. 2005. 289 f. Tese (D outorado em Ciências da Comunicação) Universidade São Paulo, Escola de Comunicações e Artes, São Paulo, 2005.

PERUZZ O, Cicília Maria Krohling. Participação nas rádios comunitárias no Brasil. In: MARQUES DE MELO, José; CASTELO BRANCO, Samantha (O rg.). Pensamento comunicacional brasileiro. São Paulo: Unesco/ Umesp, 1999. p. 71-74.

. Midia local e suas interfaces com a mídia comunitária. In: ANUÁRIO UNESCO/ UMESP DE COMUNICACÃO REGIONAL, 2003, São Paulo. Anais... São Paulo, Unesco, 2003a. p. 45.
. D a observação participante à pesquisaação em comunicação: pressupostos epistemológicos e metodológicos. In: COLO QUIO BRASIL-ITÁLIA DE CIÊNCIAS DA COMUNICAÇÃO, INTERCOM, 3., 2003, Belo Horizonte. Anais... Belo Horizonte: [s.n.], 2003b. p. 44.

D ireito à comunicação comunitária, participação popular e cidadania. In: O LIVEIRA, Maria José da Costa (O rg.). Comunicação pública. Campinas: Alínea, 2004. p. 102.

. Comunicação como direito. Palestra proferida no encontro regional de comunicação. Juiz de Fora: Tribunal Regional Federal da 4 Região, 2006.

Recebido: 29/ 09/ 2008 Received: 09/ 29/2008

Aprovado: 22/ 10/ 2008 A pproved: $10 / 22 / 1008$ 